\title{
INVESTIGATION OF FRICTIONAL STICK-SLICK EFFECT IN DISK BRAKE NVH
}

\author{
ÚRADNÍČEK Juraj ${ }^{1}$, KRAUS Pavel ${ }^{2}$, MUSIL Miloš ${ }^{2}$, BACHRATÝ Michal ${ }^{1}$ \\ ${ }^{1}$ Slovak University of Technology in Bratislava, Faculty of Mechanical Engineering, Institute of Manufacturing \\ Systems, Environmental Technology and Quality Management, Nám. slobody 17, 81231 Bratislava, Slovakia, \\ e-mail: juraj.uradnicek@stuba.sk \\ ${ }^{2}$ Slovak University of Technology in Bratislava, Faculty of Mechanical Engineering, Institute of Applied \\ Mechanics and Mechatronics, Nám. slobody 17, 81231 Bratislava, Slovakia.
}

\begin{abstract}
Paper describes the mechanism of vibration of a minimal automotive disc brake model which can lead to unwanted effects known as brake Noise Vibrations and Harshness (NVH). Stick-slip frictional effects are mathematically described by simplification of physical assumptions. Self-excited vibrations due to stick-slip and also stability conditions are defined using a 1 degree of freedom mechanical system. Non-Coulomb nonlinear behavior of the friction force with negative slope is considered. Response is obtained by the numerical solution of ordinary differential equation.
\end{abstract}

KEYWORDS: stick-slip, NVH, self-excited vibrations, brake squeal.

\section{Introduction}

Brakes represent one of the most important safety and performance components of a vehicle. They are important in terms of reliability and braking power, as well as fluent operation. The unwanted side effect of braking operation is its occasional squeal and other unwanted harshness effects. Customers understand this strange noise as a functionality defect of the brake system. This results in high warranty payouts and enormous money losses to carmakers and component producers.

$\mathrm{NVH}$ is a problem that has been challenging engineers in industry for decades. It is commonly agreed that it occurs due to a friction induced oscillation. There are several mechanisms which can lead into NVH. Most discussed are stick and slip, sprag and slip effects [1], non-conservative follower force [2] and mode coupling [3].

The stick and slip mechanism of brake squeal generation was identified by Mills in 1938 [4]. He has analyzed several drum brakes with different brake linings, where the kinetic friction coefficient was a decreasing function of sliding speed. He thought that a necessary condition for the brake squeal occurrence is the presence of a negative gradient of friction force against relative sliding velocity.

Fosberry and Holubecki in 1961 [5] suggested that the disc brake squeal can occur by a frictional pair having either a static coefficient of friction higher than the dynamic coefficient, or a dynamic coefficient which decreases with an increase in speed.

In another study performed in 1961, Spur [6] concluded that dynamic instability can occur even with considering constant coefficient of friction. The instability arises from frictional force significant increase above its normal level. The friction force increase arises from the locking action of the beam on the moving surface. This effect is called kinematic sprag-slip. 
Numerous works have analyzed the phenomenon of brake squeal, ranging from basic studies on mechanisms up to the development of suitable measurement techniques [7]. Nowadays, there is a strong research focus on numerical simulation [8]. Some years ago, mode locking was identified as the most contributing mechanism of brake squeal so stability studies in the form of eigenvalue analysis [9] of the linearized system became the state of the art. This kind of linear stability analysis is now used broadly in industry to analyze stability borders to suggest measures against squeal.

Nowadays, producers of braking components especially braking pads are strongly bounded by legislation to follow trends of sustainable reduction of environmental burdening and recyclability of materials $[10,11]$ which makes the process of developing the silent brake system even more of a challenge.

\section{Modeling of Stick-slip effect}

Stick-slip can be described as surfaces alternating between sticking to each other and sliding over each other, with a corresponding change in the force of friction. Typically, the static friction coefficient between two surfaces is larger than the kinetic friction coefficient. If an applied force is large enough to overcome the static friction, then the reduction of the friction to the kinetic friction can cause a sudden jump in the velocity of the movement. This effect can be demonstrated on a simplified representation of the brake pad/disc frictional pair represented by at least 1 degree of freedom (DOF) mechanical model (Fig. 1), where only pad elasticity in one direction is considered.

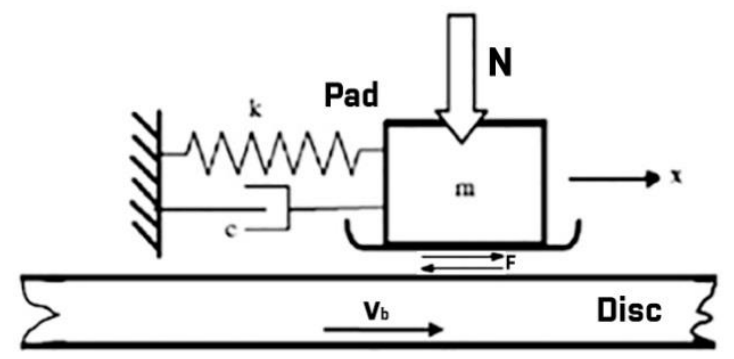

Fig. 1 Maxwell model.

The governing differential equation of the model is

$$
m \ddot{x}(t)+c \dot{x}(t)+k x(t)=F\left(t, v_{r e l}\right),
$$

where negative slope friction force is derived from [12].

$$
F\left(t, v_{r e l}\right)=N\left[\mu_{c}+\left(\mu_{\text {brk }}-\mu_{c}\right) e^{-c_{v}\left|v_{r e l}\right|} \frac{2}{\pi} \operatorname{atan}\left(s v_{r e l}\right)\right],
$$

where $m$ - friction material mass , $x$ - displacement, $c$ - damping coefficient, $k$-stiffness, relative velocity $v_{r e l}=\left(v_{b}-\dot{x}\right), v_{b}$ - disc velocity, $N$ - normal force, $\mu_{b r k}$ - breakaway friction coefficient, $\mu_{c}$ - kinetic friction coefficient, $s$ - sharpness coefficient, $c_{v}-$ coefficient, time derivatives $\dot{x}$ and $\ddot{x}$ represents velocity and acceleration of friction material in the $x$ direction. Function $2 / \pi$ atan(-) in (2) is used to represent friction force transition from positive to negative values near the zero relative velocity and to keep the friction function continuous Fig. 2.. 


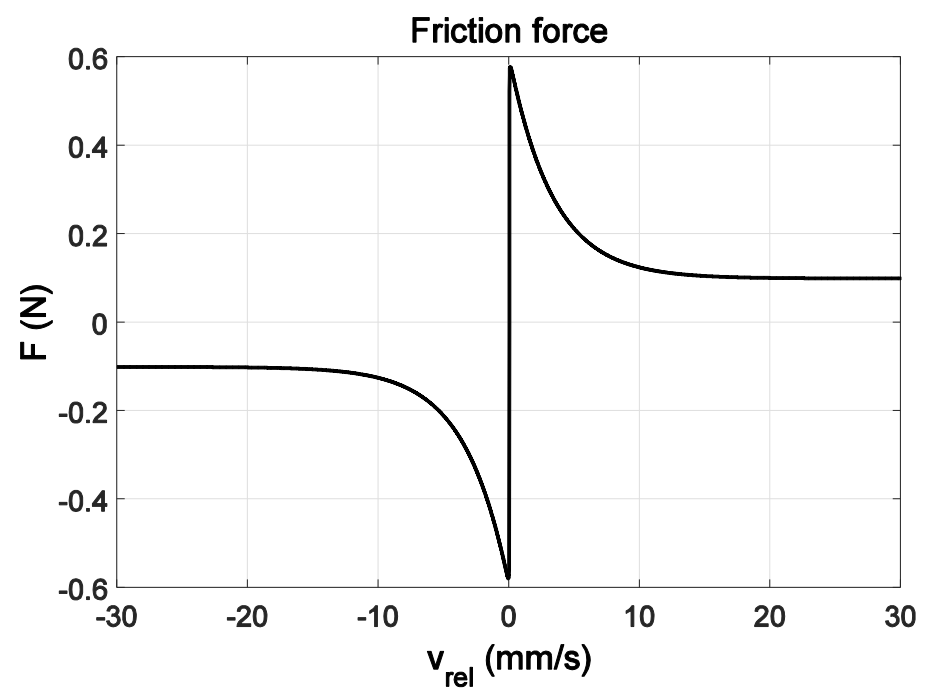

Fig. 2 Friction force functions.

Substituting (2), into (1) governing differential equation is

$$
m \ddot{x}(t)+c \dot{x}(t)+k x(t)=N\left[\mu_{c}+\left(\mu_{b r k}-\mu_{c}\right) e^{-c_{v}\left|\left(v_{b}-\dot{x}\right)\right|} \frac{2}{\pi} \operatorname{atan}\left(s\left(v_{b}-\dot{x}\right)\right)\right] .
$$

The equation (3) is nonlinear differential equation due to the nonlinear friction force changing its orientation and value with respect to relative velocity.

The response of the nonlinear dynamical system corresponding to the initial condition was calculated numerically using Runge-Kutta integration method included in MATLAB software through the ODE45 function. For all of the following calculations, constant disc speed $v_{b}(t)$ and zero initial conditions $x(0)=\dot{x}(0)=0$ have been considered.

In the first calculation, the negative slope friction force (2) and low disc velocity $v_{b}=$ $0.5 \mathrm{~mm} / \mathrm{s}$ has been considered. Under these conditions system generates self-excited vibrations with polyharmonic response (Fig.3.a) due to strong nonlinearity of the friction force. System is dynamically stable with stick-slip limit cycles Fig.3.b). Response is the combination of two motions. The first is stick motion in which the mass has the same velocity as the disc and second is the slip motion which occurs when the forces acting on the mass are greater than the friction force, which results in mass sliding over the disc.

Amplitude spectrum of the displacement response is depicted in Fig.3.c). Response consists of fundamental frequency $0.28 \mathrm{~Hz}$ and higher harmonics which are integer multiples of fundamental frequency. Fundamental frequency value is given by friction force. In general, it depends on the difference between the static and the kinetic friction force (the bigger is the friction force around zero relative velocity the longest stick mode is lasting). System under given conditions produces stable self-excited polyharmonic vibrations. 


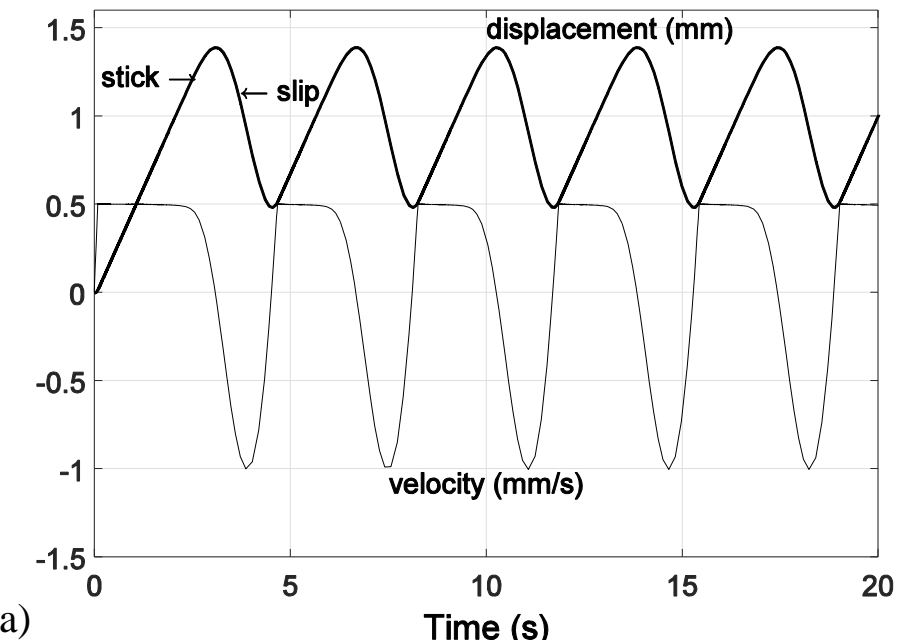

a)

Time (s)
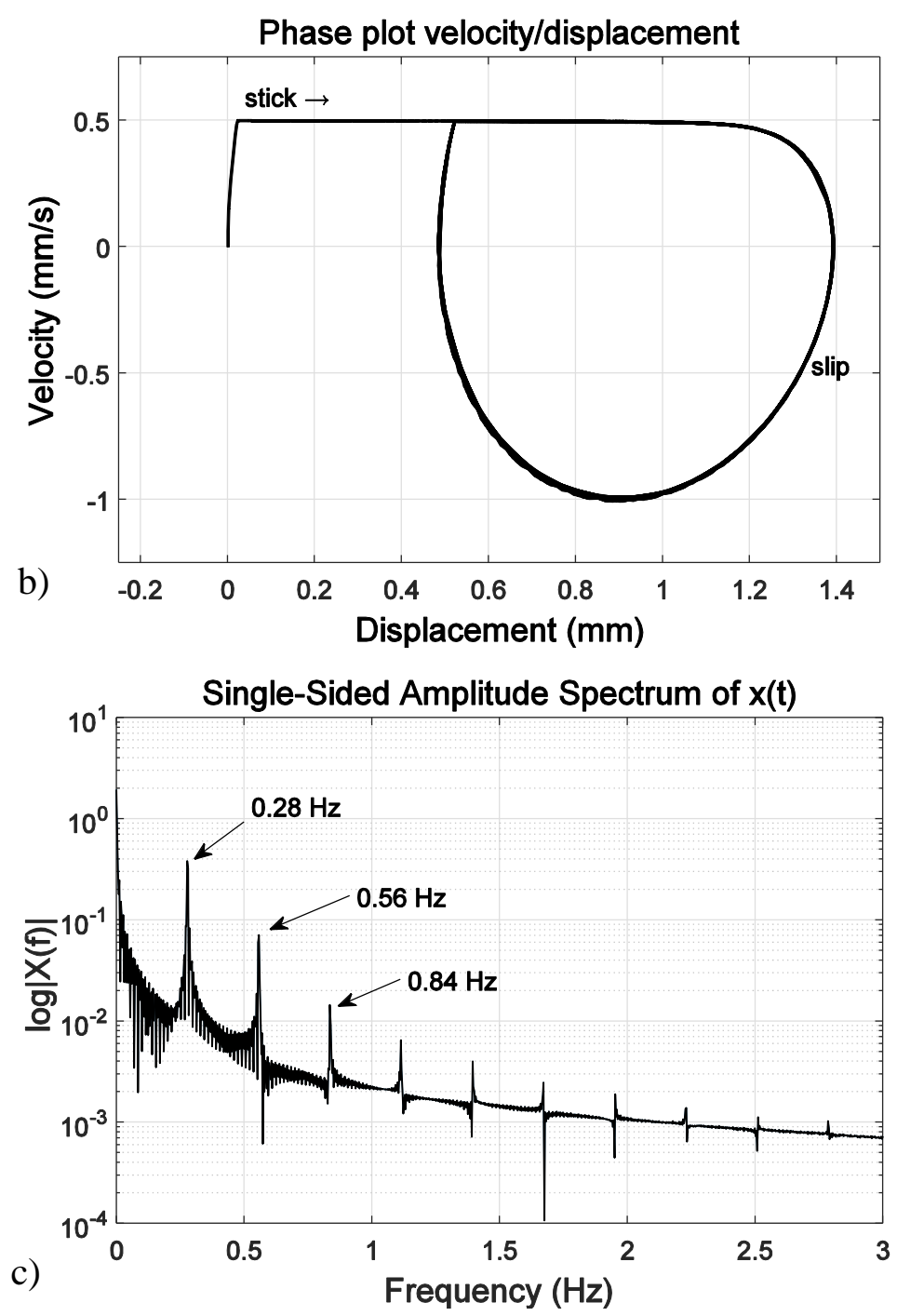

Fig. 3 Single sided amplitude spectrum

a) displacement, velocity of mass, b) phase plot of displacement/velocity of mass, c) amplitude spectrum of displacement, for parameters: $m=1 \mathrm{~kg} ; v_{b}=0.5 \mathrm{~mm} / \mathrm{s} ; k=5 \mathrm{~N} / \mathrm{mm}$; $\mu_{b r k}=0.6 ; \mu_{c}=0.1 ; c=0.2 \mathrm{~N} / \mathrm{mm} \mathrm{s}^{-1} ; N=10 \mathrm{~N} ; \mathrm{s}=500$ and initial conditions $x=0$; $d x / d t=0$. 

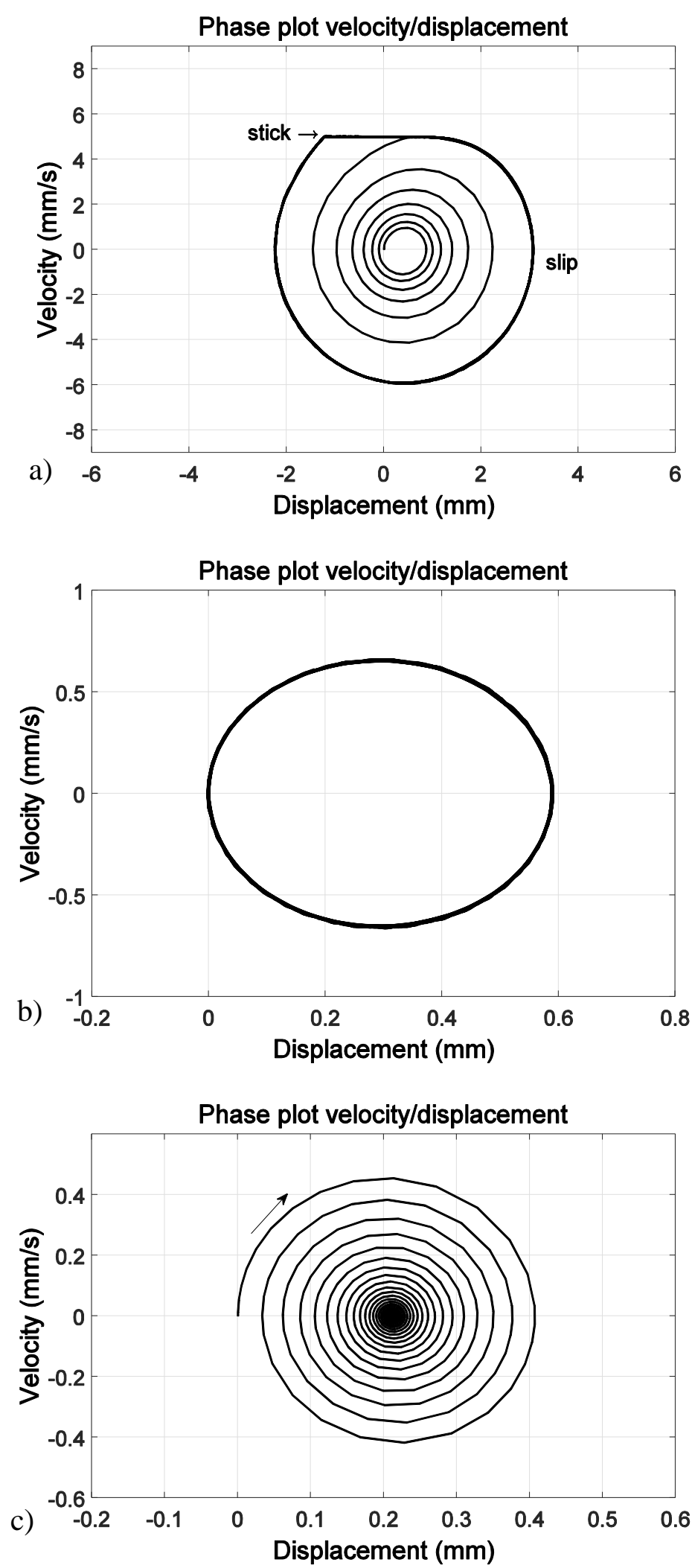

Fig. 4 Phase plot of displacement/velocity of mass

a) $v_{b}=5 \mathrm{~mm} / \mathrm{s}$, b) $\left.v_{b}=6.99 \mathrm{~mm} / \mathrm{s}, \mathrm{c}\right) v_{b}=10 \mathrm{~mm} / \mathrm{s}$.

Increasing the disc velocity $v_{b}$, the sticking phase in Fig. 4.a). is shortening, At the critical disc speed value, the stick phase do not occur anymore and system is stably oscillating along the equilibrium position Fig 4.b). When the critical base speed is exceeded, system doesn`t 
produce self-excited vibrations anymore and is oscillating about the equilibrium position with decreasing amplitude Fig 4.c). Interesting behavior can be seen in Fig. 4.a) where the amplitude of displacement and velocity is rising from zero values (initial conditions) into stick slip limit cycle. This effect is caused by the negative slope of the friction force (2) which causes negative damping in system governing equation (4). Negative damping effect has been described in more details in [13].

\section{Conclusion}

Stick-slip frictional effects have been described through single degree of freedom mechanical system. Frictional force has been modeled as a function with negative slope with respect to relative velocity. Nonlinear behavior has been demonstrated using numerical time integration of ordinary differential equation.

From the numerical analyses of simplified mechanical brake model, it can be seen, that stick-slip effect is a source of stable self-excited vibrations. When the stick-slip effect disappears due to critical velocity of the disc system is in purely sliding vibrations state. When critical velocity of the disc is exceeded, system stably oscillates about the equilibrium position with decreasing amplitude.

Negative slope of the friction force causes increasing vibration amplitude which leads to stick slip limit cycle.

In future research, the relation of Stick-slip effect to other NVH contributing mechanisms should be investigated. It can be assumed that stick-slip effect is closely related with modelock effect exhibited in multiple degree of freedom systems, where self-excited vibration energy can be transferred into the system causing two modes to exchange energy among each other resulting in a flutter type instability leading to brake squeal. In these future studies more complex system models should be considered where influencing factors such as temperature dependent system properties or friction wear models [14] should be considered.

\section{ACKNOWLEDGEMENT}

This work was supported by the Slovak Research and Development Agency under the contract No. APVV-15-0630.

\section{REFERENCES}

[1] A. Guran, et al. "Dynamics with friction: modelling, analysis and experiment, part II. ", World scientific publishing Co. Pte. Ltd., ISBN 98-128112-73, 2001.

[2] O. N. Krillov. "Nonconservative Stability Problems of Modern Physics." De Gruyter Studies in Mathematical Physics 14, ISBN 97-831102703-41, 2013.

[3] J. Úradníček, M. Musil, P. Kraus. Predicting the self-excited vibrations in automotive brake systems. In Noise and vibration in practice: peer-reviewed scientific proceedings. 1. vyd. Bratislava: Nakladatel'stvo STU, 2016, 129 - 134. ISBN 978-80227-4563-5.

[4] H.R. Mills. "Brake squeak", SAE Technical Report 9000 B, Institution of Automobile Engineers, 1938

[5] R. A. C. Fosberry, Z. Holubecki. Disc brake squeal: its mechanism and suppression. Technical Report 1961/1, Motor Industry Research Association, Warwickshire, England, 1961. 
[6] R. T. Spurr. A theory of brake squeal. Proceedings of the Automobile Division, Institution of Mechanical Engineers, 1961-1962 (1), 33 - 52, 1961.

[7] N. M. Kinkaid, O. M. O'reilly, P. Papadopulos. Automotive disc brake squeal. Journal of Sound and Vibration 267, 2003, 105 - 166.

[8] G. Dihua, J. Dongying. A study on disc brake squeal using finite element methods, Proceedings of International SAE Congress and Exposition, 1998.

[9] A. Suchal. Influence of Thermal Effect on Dynamics of Disc Brakes and Brake Squeal Propensity. PhD. Thesis, Slovak University of Technology in Bratislava, Slovakia, 2013.

[10] M. Peciar, R. Fekete, P. Peciar. Agglomeration Technologies of Processing Powder Wastes, Solid State Phenomena, 2016 (244), 121 - 129.

[11] P. Peciar, M. Eckert, R. Fekete, R. Hrnčiar. Analysis of pharmaceutical excipient MCC Avicel ph102 using compaction equations. Journal of Mechanical Engineering - Strojnícky časopis, 2016 (66), No. 1, 65 - 82

[12] B. Armstrong, C.C. de Wit, "Friction Modeling and Compensation", The Control Handbook, CRC Press, 1995.

[13] J. Úradníček, P. Kraus, M. Musil. Investigation o the frictional stick slip and sprag slip mechanisms leading to disc brake noise vibration and harshness effects. In Aplimat 2017: proceedings of the 16th conference on applied mathematics 2017. Bratislava, 31.1.-2. 2. 2017. 1st. ed. Bratislava : Vydavatel'stvo STU, 2017, ISBN 978-80-2274649-6.

[14] M. Šofer, R. Fajkoš, R. Halama. Influence of Induction Hardening on Wear Resistance in Case of Rolling Contact. Journal of Mechanical Engineering - Strojnícky časopis 2016 (66), No. 1, 17 - 26. 
